\title{
Obstructive sleep apnea uncovered after high spinal anesthesia: a case report
}

\author{
[L’apnée obstructive du sommeil répélée après une rachianesthésie haute : \\ une présentation de cas]
}

Paul M. Wieczorek MDCM, Francesco Carli MD MPHIL FRCA FRCPC

Purpose: To illustrate how a patient's previously undiagnosed obstructive sleep apnea was uncovered after administration of a spinal anesthetic with a high sensory blockade, and to discuss possible explanations for this occurrence and anesthetic implications.

Clinical features: A 55-yr-old male presented for osteotomy and open reduction and internal fixation of his left femur secondary to malunion from a previous fracture. Past medical history consisted of hypertension, hypercholesterolemia, bipolar disorder, gastroesophageal reflux disease, and cluster headaches. A combined spinalepidural technique was chosen. Isobaric bupivacaine $0.5 \%$ ( $15 \mathrm{mg}$ ), was provided for the spinal anesthetic, along with I mg iv midazolam for procedural sedation and $0.5 \mathrm{mg}$ iv droperidol for mild nausea. Throughout the operation, many apneic events were noted, often with respiratory efforts. The patient was easily arousable during each event and would breathe normally until the next episode. Vital signs remained stable throughout. Postoperative respirology consultation was requested, and a sleep study revealed severe obstructive sleep apnea. The patient was subsequently started on continuous positive airway pressure with marked improvement in symptoms, including the cluster headaches.

Conclusion: Recent literature suggests that high spinal blockade can result in altered levels of arousal by producing a de-afferentation of peripheral proprioceptive and sensory stimuli necessary for maintaining an awake state. In patients predisposed to upper airway obstruction, decreasing the level of consciousness can result in airway obstruction as occurs during sleep in these patients. This serves to underline the importance of considering capnography for all cases utilizing a neuraxial anesthestic technique.
Objectif : Illustrer comment une apnée obstructive du sommeil, non diagnostiquée auparavant, a été découverte après une rachianesthésie avec blocage sensitif haut et discuter des explications possibles de cette situation et des implications anesthétiques.

Éléments cliniques: Un homme de 55 ans devait subir une ostéotomie et une réduction chirurgicale et une fixation interne du fémur gauche à cause du cal vicieux d'une fracture antérieure. II présentait des antécédents d'hypertension, d'hypercholestérolémie, de désordres bipolaires, de reflux gastro-œsophagien et de céphalée vasculaire de Horton. L'anesthésie rachidienne-péridurale combinée a été choisie. De la bupivacaïne isobare à 0,5 \% (15 mg) a été utilisée avec I mg de midazolam iv pour la sédation et $0,5 \mathrm{mg}$ de dropéridol iv pour les nausées modérées. De nombreux incidents apnéiques peropératoires ont été notés, souvent avec des efforts respiratoires. On pouvait facilement réveiller le patient pendant chaque incident. II respirait normalement jusqu'à l'épisode suivant. Les signes vitaux sont demeurés stables pendant toute l'opération. Lors d'une consultation postopératoire demandée en pneumologie, l'étude du sommeil a révélé une sévère apnée obstructive. On a donc utilisé une thérapie respiratoire à pression expiratoire positive continue et le patient a vu ses symptômes réduits de façon marquée, y compris la céphalée vasculaire de Horton.

Conclusion : Des publications récentes indiquent qu'un bloc rachidien haut peut modifier les niveaux d'éveil en empêchant la propagation des stimuli afférents sensitifs et proprioceptifs périphériques nécessaires pour le maintien de l'éveil. Chez les patients prédisposés à une obstruction des voies aériennes supérieures, la baisse du niveau de conscience peut produire une obstruction des voies aériennes comme celle qui survient pendant le sommeil chez ces patients. Ces données soulignent l'importance de considérer la capnographie pour tous les cas où on utilise une technique anesthésique neuraxiale.

From the Department of Anesthesia, McGill University Health Center - Montreal General Hospital, Montreal, Quebec, Canada. Address correspondence to: Dr. Francesco Carli, Department of Anesthesia, Dl0-144, Montreal General Hospital, 1630 Cedar Av.,

Montreal, Quebec H3G 1A4, Canada. Phone: 514-934-1934; E-mail: franco.carli@mcgill.ca; or paul.wieczorek@mail.mcgill.ca Accepted for publication September 29, 2004. Revision accepted February 21, 2005. 


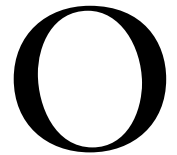

BSTRUCTIVE sleep apnea is an often underdiagnosed condition where a patient's upper airway obstructs during sleep at night. ${ }^{1,2}$ Not only can resultant chronic hypoxia make patients susceptible to various illnesses (hypertension, myocardial infarction, etc.), but their quality of life may be severely impaired (excessive daytime somnolence). ${ }^{1,3}$ This sleep pathology is often encountered in the obese population. ${ }^{1}$ This case report serves to illustrate how a patient's previously undiagnosed obstructive sleep apnea was uncovered during neuraxial anesthesia with a high spinal blockade.

\section{Case report}

A 55-yr-old male, weight $86 \mathrm{~kg}$ and height $170 \mathrm{~cm}$ (body mass index $29.8 \mathrm{~kg} \cdot \mathrm{m}^{-2}$ ), presented for osteotomy and open reduction and internal fixation of the left femur secondary to malunion from a femoral fracture. The patient's past medical history included hypertension, hypercholesterolemia, bipolar disorder, and gastroesophageal reflux disease. In addition, he had been suffering for 11 years from cluster headaches which had been diagnosed by a neurologist. Medications included verapamil, simvastatin, lithium, valproic acid, sumatriptan, omeprazole, and bupropion. The patient had presented one year earlier with an open grade III femoral fracture. Initial surgery to repair the fracture was performed under general anesthesia with patient controlled analgesia for postoperative pain. Because of a delayed emergence, the patient was transferred to the postanesthetic care unit (PACU) and remained intubated for one hour. Postoperatively, the physiotherapist on the ward had observed abnormal breathing patterns during sleep consisting of two normal breaths followed by a long pause, occurring on several occasions during the patient's stay in hospital. No follow-up was ordered.

A combined spinal-epidural technique was chosen for the present surgery. Following application of standard monitors including an electrocardiogram monitor, non-invasive blood pressure monitor, and pulse oximeter, midazolam $\mathrm{l} \mathrm{mg}$ iv was administered for procedural sedation. The epidural space was located easily at the L3-L4 interspace, and spinal anesthesia was provided with $15 \mathrm{mg}$ of $0.5 \%$ isobaric bupivacaine after a clear CSF tap. The epidural catheter was easily inserted with no blood, cerebrospinal fluid, or paresthesias noted. Droperidol, $0.5 \mathrm{mg} i v$, was given $15 \mathrm{~min}$ after the beginning of surgery for mild nausea with no resultant change in vital signs. A Tl sensory level was achieved initially, which receded to a T4 sensory level at approximately one hour and $45 \mathrm{~min}$ into the surgery.
Capnography was used to monitor the patient's pattern of breathing throughout the case. During the course of the procedure, multiple apneic episodes were noted, often associated with respiratory efforts. The events occurred on a regular basis and would be preceded by the patient drifting asleep and closing his eyes. During each apneic episode, however, the patient remained easily arousable and would continue to breathe normally until the next apneic event. When aroused, the patient would be alert, oriented, and responsive. As the block receded, the frequency of apneic spells declined. Vital signs throughout the procedure remained stable, with a heart rate between 70 to 80 beats. $\mathrm{min}^{-1}$, blood pressure 120/60 (which had increased to 140/65 one hour and $45 \mathrm{~min}$ into the operation), and a stable oxygen saturation between 98 to $99 \%$ on $5 \mathrm{~L} \cdot \mathrm{min}^{-1}$ oxygen by mask. Ephedrine $5 \mathrm{mg} i \mathrm{p}$ was administered on three occasions to treat mild hypotension which recovered immediately. The entire surgical procedure lasted two hours and $25 \mathrm{~min}$ without any intraoperative complications. The patient was then transferred to the PACU in stable condition. Epidural bupivacaine 0.1\% (without opioids) was administered at a rate of 6 $\mathrm{mL} \cdot \mathrm{hr}-\mathrm{l}$ for pain control. During the two-hour PACU stay, an apneic episode was observed by the nurses, resulting in a desaturation to $91 \%$ which recovered quickly. Oxygen saturation on the ward ranged from 96\% when the patient was experiencing pain to $93 \%$ when the patient was pain free. Because of a high suspicion of obstructive sleep apnea, a postoperative respirology consultation was ordered. Further questioning revealed over seven years of witnessed snoring, difficulty staying awake during the day, choking at night, awakening from sleep multiple times during the night, morning fatigue, and memory loss. The sleep study performed was consistent with severe obstructive sleep apnea with a $67 \%$ sleep efficiency and an apneahypopnea index of 60.6. The oxygen saturation nadir reached $82 \%$. There was no improvement with changes in position. All stages of sleep were entered. The patient was started on $10 \mathrm{~cm} \mathrm{H}_{2} \mathrm{O}$ nasal continuous positive airway pressure resulting in considerable symptomatic improvement, and was eventually titrated up to $14 \mathrm{~cm} \mathrm{H}_{2} \mathrm{O}$ in gradual increments. The cluster headaches were almost completely eliminated by the continuous positive airway pressure therapy.

\section{Discussion}

This report illustrates how undiagnosed obstructive sleep apnea was uncovered after a high neuraxial block was administered. The relation between obstructive sleep apnea and neuraxial anesthesia, therefore, becomes increasingly important to understand. 
There is mounting evidence that spinal anesthesia in itself produces sedation. Gentili et al. ${ }^{4}$ studied groups of patients receiving hyperbaric bupivacaine and found an increasing degree of sedation as the level of the spinal block became higher. A second group of patients, in whom midazolam $1 \mathrm{mg}$ iv increments were added, revealed an additive effect on sedation. Pollock et al..$^{5}$ demonstrated that in unpremedicated patients receiving spinal lidocaine, both the Assessment of Alertness/Sedation Scale and a selfsedation scale diminished in comparison with patients receiving a spinal placebo. A proposed mechanism for this effect is de-afferentation from proprioceptive and sensory stimuli to the central nervous system caused by spinal blockade; these inputs are likely involved in maintaining patients in the awake state. This may have explained the tendency of this patient to experience repeated apneas during the course of his spinal anesthetic. As described above, patients with obstructive sleep apnea have a tendency to obstruct their airway during sleep and somnolent states. The pathophysiologic mechanism includes several factors such as relaxation of the pharyngeal muscles in combination with a variety of upper airway abnormalities. ${ }^{1}$ In addition, a large percentage of obese patients, as was the case with this patient, have underlying obstructive sleep apnea. ${ }^{1,2}$ In this setting, the peripheral stimulation required for the patient to maintain an awake state was severed by the spinal anesthetic. The result of this deafferentation caused him to enter a plane of somnolence, therefore allowing his obstructive sleep apnea to manifest as it does during sleep.

Epidural analgesia has also been associated with decreased minimum alveolar concentration requirements when combined with general anesthesia, ${ }^{6}$ again supporting the de-afferentation phenomenon. If one extrapolates this finding to the postoperative period where local anesthetic infusions are used for analgesia, this may partially explain the observation that this patient's saturation decreased on the ward when pain was well controlled (reduced afferent signals). There have been reports in the literature ${ }^{7}$ regarding the use of neuraxial opioids in patients with known or suspected obstructive sleep apnea. Perioperative opioids in this patient population have been associated with adverse events, including respiratory and circulatory arrest. This effect is not isolated to the immediate postoperative period. Opioids were not included as part of the anesthetic management in this case, either intraoperatively or postoperatively. Despite this, the patient still experienced apneic events, thereby eliminating opioid use as a cause of sedation. The avoidance of opioid administration may, in fact, explain why the patient did not expe- rience severe apnea to the point of desaturation, and he remained easily arousable.

Other causes for increased somnolence were excluded. The patient did not receive appreciable doses of sedative medications, the hemodynamics remained stable ensuring adequate brain perfusion, arterial oxygen saturation remained unchanged, and an intraoperative glucose measurement was normal.

This case serves to underline the importance of considering additional intraoperative monitoring above that suggested in current guidelines. A Although an evaluation of respiration for regional anesthesia is required, capnography for regional anesthesia is not mandatory. Observing the chest can be difficult, especially when full-body drapes are applied and the chest is not directly visible. This is also impractical as it requires constant observation of the patient in an environment where the anesthesiologist must perform other tasks (charting vital signs, preparing medications, etc.). Capnography to assess the pattern of breathing is easy to apply, and provides the additional benefit of an apnea alarm. Our experience leads us to suggest that all patients who have received neuraxial anesthesia should be monitored with capnography, regardless of their past medical history. This is particularly true if sedation is required, as it has been shown that patients with spinal anesthetics exhibit increased sensitivity to sedating agents. ${ }^{4,8}$

In summary, obstructive sleep apnea is a disease whose primary pathology manifests when the patient is either asleep or in a state of altered arousal, where the upper airway can obstruct. This situation can be replicated with a high spinal anesthetic, where deafferentation of peripheral stimuli may result in an altered level of arousal. This is an important consideration, as the disease may manifest itself for the first time during the course of anesthesia. We suggest complete respiratory monitoring should be applied for cases involving neuraxial regional techniques.

\section{References}

1 Gami AS, Caples SM, Somers VK. Obesity and obstructive sleep apnea. Endocrinol Metab Clin North Am 2003; 32: 869-94.

2 Silverberg DS, Iaina A, Oksenberg A. Treating obstructive sleep apnea improves essential hypertension and quality of life. Am Fam Physician 2002; 65: 229-36.

3 Hudgel DW. Treatment of obstructive sleep apnea. A review. Chest 1996; 109: 1346-58.

A ASA Guideline Standards for Basic Anesthetic Monitoring, October 2003. 
4 Gentili M, Chau Hun P, Enel D, Hollande J, Bonnet F. Sedation depends on the level of sensory block induced by spinal anaesthesia. Br J Anaesth 1998; 81: 970-1.

5 Pollock JE, Neal JM, Liu SS, Burkhead D, Polissar N. Sedation during spinal anesthesia. Anesthesiology 2000; 93: 728-34.

6 Hodgson PS, Liu SS, Gras TW. Does epidural anesthesia have general anesthetic effects? A prospective, randomized, double-blind, placebo-controlled trial.

Anesthesiology 1999; 91: 1687-92.

7 Ostermeier AM, Roizen MF, Hautkappe M, Klock PA, Klafta JM. Three sudden postoperative respiratory arrests associated with epidural opioids in patients with sleep apnea. Anesth Analg 1997; 85: 452-60.

8 Ben-David B, Vaida S, Gaitini L. The influence of high spinal anesthesia on sensitivity to midazolam sedation. Anesth Analg 1995; 81: 525-8. 